\title{
Fostering the sleep instructional guidelines for nursing students regarding their sleep quality, academic performance and psychosocial behavior
}

\author{
Nahed Saied Mohamed El-Nagger, Orban Ragab Bayoumi \\ Faculty of Nursing, Ain Shams University, Egypt
}

Received: April 6, 2019

DOI: $10.5430 /$ jnep.v10n1p43
Accepted: July 26, 2019

Online Published: September 23, 2019

\begin{abstract}
Background and Objective: Sleep is a basic human need and has a necessary role in individual's life, functioning, overall health and well-being. Sleep is necessary for college students' intellectual, emotional and physical health, also for their cognitive performance that significantly affected by sleep quality. Aim: To investigate the effect of fostering the sleep instructional guidelines for nursing students regarding their sleep quality, academic performance and psychosocial behavior.

Methods: Design: A quasi-experimental study design was utilized. Setting: Faculty of Nursing at Umm Al-Qura University in Makkah Al-Mukramh affiliated to the Ministry of Education in the Kingdom of Saudi Arabia (KSA). Sample: A purposive sample composed of 85 males and females nursing students from all academic years. Tools: Three tools were used Pre \& Post including: (1) A self-administered Questionnaire Sheet, (2) Epworth Sleepiness Scale (ESS), and (3) Pittsburgh Sleep Quality Index (PSQI).

Results: Slightly more than three quarters (78.82\%) of nursing students their ages were ranged from $20-22$ years and $69.41 \%$ of them were females. More than one fourth (27.06\%) of students were having good sleep and $72.94 \%$ of them had poor sleep pre the sleep instructional guidelines compared with $81.18 \%$ and $18.82 \%$ of them post providing the instructional guidelines respectively.

Conclusions: Fostering the instructional guidelines regarding sleep had positive effects on nursing students' sleep patterns in the form of sleep quality, bedtime at night, sleeping latency, sleeping efficiency and disturbances. In addition to enhancing students' academic performance and modifying their psychosocial behavior regarding daytime dysfunction, coffee consuming in the evening, bedroom environment, social isolation, and use of social media. Recommendations: Future research should carry out for university students' sleep patterns on a broad category as a regional research project all over the Kingdom of Saudi Arabia (KSA) involving multidisciplinary team as doctors, nurses, psychologists, sociologists and nutritionists.
\end{abstract}

Key Words: Instructional guidelines, Nursing students, Sleep quality, Academic performance, Psychosocial behavior.

\section{INTRODUCTION}

Sleep is a basic human need and has a necessary role in individual's life, functioning, overall health and well-being. ${ }^{[1,2]}$ Sleep is necessary for college students' intellectual, emotional and physical health, also for their cognitive perfor- mance that significantly affected by sleep quality. As well as, sleep is a repetitive, an active and reversible behavior having different functions, such as learning and restorative processes, in addition to repair and growth. ${ }^{[3,4]}$ Additionally, Sleep gives the body a chance to rest and allows the

*Correspondence: Nahed Saied Mohamed El-Nagger; Email: nahidalngar@yahoo.com; Address: Faculty of Nursing, Ain Shams University, Egypt. 
mind to build pathways necessary to create memories, learn and maintaining the equilibrium of student's psychosocial behavior. $^{[5]}$

On the other hand, sleep-wake cycle is one of the biological rhythms which are determined by a circadian timing system that predisposed by some factors like physiological function and work schedules. ${ }^{[3,4]}$ So, sleep loss makes individuals feel sleepy in the daytime, also it is a possible risk factor for Alzheimer's disease. Whereas, all of these occur throughout the body and the brain. ${ }^{[5,6]}$

Habitual sleeping patterns undergo intrinsic changes from childhood to adolescence. These changes characterized by progressive delay in sleep phase without decreasing in the need for sleep. At the same time, schedules frequently require earlier wake times and leads to shorter Total Sleep Time (TST). Also, sleep debt accumulated during the week often leads to catch-up sleep or prolonged sleep periods on weekends causing severe day to day irregularities of sleep patterns in adolescents. ${ }^{[7,8]}$

Sleep quality refers to a collection of sleep measures including; Sleep Onset Latency (SOL), TST, sleep efficiency, total wake time, degree of fragmentation and sleep disruptive events such as spontaneous apnea. Good sleep quality is associated with positive outcomes including well-being, better health, better psychological functioning and less daytime sleepiness. However, quality of sleep isn't directly associated with sleep quantity. ${ }^{[9,10]}$

Good sleep quantity and quality are essential for promoting of physiological processes. Whereas, adolescents require to sleep at least 8.5 to 9.25 hours each night. However, insufficient sleep and neglecting to get the mended amount of sleep per night has a negative influence on next day functions also, can be malicious to long-term health and even life. ${ }^{[8]}$ Sleep is a food and core for the brain, when hungry for sleep, the brain becomes uncompromised, and cause decreased levels of concentration and feelings of sleepiness. ${ }^{[1]}$ Therefore, sleep is very important to nursing student because they must achieve both professional learning and clinical capacity. ${ }^{[10,12]}$

Cognitive performance is significantly affected by sleep quality, because of the correlation between sleep and memory formation and learning, sleep is of important to college students. ${ }^{[10]}$ Changes in sleep patterns commonly observed commonly among adolescence and shown an impact on their academic, neurocognitive, and psychological well-being. Insufficient sleep, whether manifested as alteration in sleep quantity and quality, and is commonly noted among adolescents. $^{[11,12]}$

Nursing students are facing variety of stressful situations during the university period including; those which stimulate the development and professional maturing, health and quality of life and those which threaten their well-being. ${ }^{[13]}$ Previous researches have been evaluated the sleep of nursing, pharmacy, and students, they pointed out that sleep disorders and difficulties were common among Saudi Arabian nursing and medical students with decreased their academic achievement. In addition, insomnia and poor quality of sleep were widespread with unsatisfactory psychosocial behavior among nursing students. ${ }^{[10,14,15]}$

Nursing students experiences the pressing need to work and maintain their social lives while balancing extensive class and study time. ${ }^{[5,13]}$ In this context, researches have been founded that fifty percent of nursing students were suffering from daytime sleepiness and nearly three fourths weren't obtaining sufficient sleep, that affecting their grade point averages, the risk of academic failure, and cause accidents. ${ }^{[13,16]}$ Furthermore, a high proportion of nursing students are suffering from sleeping disturbances that accompanied with physical and psychological complains such as headaches, back pain, depression, anxiety and gastro esophageal reflux. ${ }^{[3,11]}$ Therefore, sleep is very important to nursing student because they must achieve both professional learning and clinical capacity. ${ }^{[10,12]}$

The sleeping medicine emphasized the importance of sleep for academic, psychosocial and for all normal activities. Also, researches have shown that adequate sleep helps to increase attention, learning and creativity and aid in coping with change, problem solving, making decisions and controlling emotions. ${ }^{[3,13]}$ In turn, it is important to instruct the students adhere to a sleep schedule of the same bedtime and wake up time, even on the weekends. This helps to regulate body's clock and could help for fall asleep and stay asleep for the night, also practice a relaxing bedtime ritual; throughout a relaxing, routine activity right before bedtime conducted away from bright lights helps separate sleep time from activities that can cause excitement or anxiety which can make it more difficult to fall asleep. In addition, avoid naps in the afternoon if they have sleeping disturbances. ${ }^{[9,15]}$

Researches have been founded that, regular exercise improves sleep length, sleep quality, reduced sleep onset delay, and improved sleep efficiency. Also, physical activity considers a component in overall wellness and is necessary in order to remain active and healthy. Consequently, encourage the students to exercise daily and evaluate the sleep room and environment to establish the needed sleep conditions, keeping cool bedroom and free from light and noise, sleeping on a comfortable pillows and mattress. ${ }^{[3,17]}$

Moreover, aromatherapy with essential oils is one of the 
most popular complementary medical tools for improving sleep quality. ${ }^{[8,15]}$ On the other hand, it is best to take work materials, computers and televisions out of the sleeping environment. ${ }^{[18,19]}$ Additionally, inform the student to avoid spicy and heavy meals for 2-3 hours pre bedtime at night. ${ }^{[8,9]}$

\subsection{Significance of the problem}

A specific subset of college students is baccalaureate-nursing students. Nursing is a demanding profession with occupational stress, which involves academics, shift duties, and sleep deprivation. Nursing students are vulnerable group young adult, they have a rigorous course load, which necessitates adequate sleep. ${ }^{[6,11]}$ So, sleep has founded to be on the bottom of the priority list of most nursing students because they feel that must always meet up with deadlines. The previous studies have been considered the negative effects of insufficient sleep on students and emphasized on the need to study how inadequate sleep pattern can affect the sleeping quality of undergraduates nursing students and negatively affect their life. ${ }^{[11,18]}$

Previous studies have estimated that between $14 \%$ and $33 \%$ of adolescents have sleep problems and $10 \%$ to $40 \%$ of nursing student's experience moderate or transient sleep deprivation. Sleep insufficiency and problems influence college student performance, behavior, and mood during daytime hours and increase risks for injuries, major depression, drug use, and suicidal behavior. On other hand, sleep changes during adolescence are associated with multiple biological, developmental, psychosocial, cultural, familial, and academic factors. ${ }^{[8,12]}$

Furthermore, bad individual's sleep quality has an adverse effect on the quality of individual's life, as it causes increasing morbidity due to physical dysfunctions and psychosocial stress, aging early, depression, kidney impairment, and glucose disturbances, learning difficulty and decreased efficiency at work. In addition, nursing students are the future of nursing as a profession, their health and well-being will play a role in the quality of nursing in the future. ${ }^{[14,15]}$

\subsection{Aim of the study}

The aim of this study was to investigate the effect of fostering the sleep instructional guidelines for nursing students regarding their sleep quality, academic performance and psychosocial behavior through:

1) Assessing the sleep patterns, the factors that influence the quality of sleep, sleep disturbances, daytime sleepiness and its influence on academics, and routine activities of daily life among nursing students.

2) Determining which social demographic and academic variants that interfere with sleep quality.

Published by Sciedu Press
3) Designing and disseminating the sleep instructional guidelines for nursing students.

\subsection{Research Hypotheses}

This study hypothesized that

1) Decreasing sleep duration, late bedtimes during weekdays and weekends, and increasing daytime sleepiness will negatively associated with poor academic performance of nursing students.

2) Fostering the sleep instructional guidelines on nursing students regarding sleep as basic human needs will be associated with improving their sleep quality, academic performance and psychosocial behavior.

\section{SUBJECTS AND METHODS}

\subsection{Research design}

A quasi-experimental study design was utilized.

\subsection{Research setting}

This study conducted in the Faculty of Nursing at Umm Al-Qura University in Makkah Al-Mukramh, affiliated to the Ministry of Education in the Kingdom of Saudi Arabia (KSA).

\subsection{Research subjects}

Sample Size and Characteristics: Purposive sample of eightyfive nursing students from all academic years (second, third, and fourth year students) chosen from the previously mentioned setting.

The research subjects were chosen according to the following inclusion and exclusion criteria:

\section{Inclusion criteria:}

- Both gender: Males and females undergraduate nursing students.

- Age: $>20$ years, $\leq 22$ years.

Exclusion criteria:

Nursing students who were suffering from chronic diseases.

\subsection{Tools of data collection}

Three tools used for data collection via the website link (https ://docs.google.com/forms/d/1aUIgwZRE7Zf 2QkqqZKmd7_c4zg4E3JYMUOuIBimgIzw/viewform?ed it_requested=true).

1) A self-administered Questionnaire Sheet (Pre/Post): It designed by the researchers in simple English and Arabic languages after reviewing of relevant literature to collect data about the nursing students. Open, close ended, and multiplechoice questions are used. The time consumed to fill the 
questionnaire sheet by each student was 5-10 minutes. It includes three parts:

A. Nursing student's socio-demographic characteristics such as: age, gender, academic year, social circumstance i.e. marital status, type of family, roommate or bed sharing, etc.

B. Nursing student's sleep states such as: sleep patterns, problems, disturbances and deprivations, in addition to risk factors of psychosocial and behavior such as medication use for sleeping, use of coffee in the evening, use of social media and internet, social isolation, anger, fear, anxiety and depression, etc.

C. Academic Performance and Missed Class Attendance: It was used to:

- Assess the students' academic performance by using student self-evaluation of the last month exams before fostering the sleep instructional guidelines (Pre).

- Re-assessed the students' academic performance after fostering the sleep instructional guidelines by one month (Post). Accordingly, the students' academic performance categorized as "good, average, and poor" performance as perceived by themselves.

- In addition, students asked about missing class attendance and its frequency in the last month (Pre), in comparison with student's class attendance after fostering the sleep instructional guidelines by one month (Post). Accordingly, students' responses categorized into none, 1-6 days, 7-14 days and $\geq 15$ days.

2) Epworth Sleepiness Scale (ESS) (Pre/Post): It was adopted from Al Ghamdi (2013) and Johns (2010). ${ }^{[10,16]}$ It was used to assess the student's daytime sleepiness in the last month (Pre) and re-assessed after fostering the sleep instructional guidelines by one month (post). It is a standardized validated scale in an English language that assesses the liability that nursing students falling asleep in certain situations. It consists of "8 statements" explaining different students' daily living situations and it scored from "Zero to Three" according to chance of student's dozing. Whereas, "Zero" score for no chance of dozing (would never doze), "One" score for mild chance of student's doze, "Two" score for moderate chance of student's doze and "Three" score for high chance of student's doze. The total score of this scale ranges from "0-24". Accordingly, if the student's score was " $1-6$ " considered get "Enough Sleep", if he/she score was "7-8" considered get "Average Sleep", meanwhile if he/she score was "Nine and up" considered "Need to seek the advice of a sleep specialist without delay". Each student took about 3-5 minutes in filling the ESS scale.

3) Pittsburgh Sleep Quality Index (PSQI) (Pre/Post): It was adopted from Aung et al. (2016) and Buysse et al.
(2009). ${ }^{[20,21]}$ It is in English language and used to relate the student's sleep habits during assessment according to most days and nights in the last month (Pre) and is re-assessed after the instructional guidelines by one month (Post). The PSQI scale aimed to differentiate between good and poor sleepers. The PSQI contains 19 self-rated questions, and five questions rated by the bed sharing or roommate (if available); only self-rated questions were included in the scoring. The PSQI 19 self-rated items combined to form "seven components"; involving sleep duration, sleep disturbances, habitual sleep efficiency, subjective sleep quality, and use of sleep medication, daytime dysfunction and sleep latency. The score of each component ranges from "0-3" points. In all answers, a score of "Zero" indicates no difficulty, while a score of "3" indicates severe difficulty or the greatest dysfunction. Summation of sleep components scores to make the total sleep quality score that ranges from " 0 to 21 ". If student's score "Greater than Five" they are having "Poor sleep quality" and when their score "Less than or Equal to Five" they are having "Good sleep quality". Each student took about 5-10 minutes in filling PSQI scale.

\subsection{Validity and reliability}

The tools were validated by three academic experts in the field, they reviewed the tools for its clarity, relevance, comprehensiveness and simplicity. Minor modifications were done in the form of rephrasing some statements. The tools were tested for reliability using Cronbach's alpha test. A very good internal consistency was detected, where the test value reached 0.721 for Epworth Sleepiness Scale, and 0.83 for Pittsburgh Sleep Quality Index.

\subsection{Phases of study application}

\section{1) Preparatory phase}

A review of the past, current local and international related literature covering all aspects of the study using available magazines, books and journals carried out to be appropriate with research problem, prepare the tools, and guide in preparation of "Sleep Instructional Guidelines".

Sleep Instructional Guidelines Booklet Preparation: The sleep instructional guidelines booklet prepared by the researchers after reviewing of the related literature. It designed in simple English and Arabic languages. The booklet included illustrations and figures. Also, it was evaluated for its content and clarity by a group of experts from academic staff members. Their opinions were taken into researchers' considerations. After feedback, the booklet was revised and produced in its final form and disseminated by the researchers to the students through their email. The sleep instructional guidelines booklet included; concept of sleep, importance of 
sleep, sleep patterns, sleep disturbances and deprivation, tips and guidelines for improving sleep quality.

\section{2) Exploratory phase}

A. Pilot study: It carried out on ten percent of the study sample (9 nursing students) to test the content validity, feasibility and clarity of study tools and the time needed to fill each tool. Some necessary modifications such as adding, omission questions or more clarifications for some questions in the study tools were carried out. Taking into consideration the results of the pilot study and the revised final form then used. Evaluation of the contents of the booklet, and the simplicity of language also done to serve as background personal information after its content discussed with the researchers. The subjects included in pilot study were excluded from the sample of the study later.

B. Field Work: The actual fieldwork was carried out at the beginning of October 2017 to the end of November 2017 to collect the research data and apply the study. The researchers were available in the Faculty of Nursing 2 days/week for the first two weeks from 8 am to $1 \mathrm{pm}$ at Wednesday and Thursday to clarifies the aim of the study to the students and giving them the previously mentioned online link on the website, after that the students were filling the study tools online. The average number of students filling the study tools daily ranged between 3-4 students.

\subsection{Procedures}

- Assessing the nursing students for inclusion and exclusion criteria.

- Selecting the students after obtaining their agreement for participation in the study.

- Documenting the students' names and emails.

- Explaining the students with an overview of the study including the aim and the procedures of the study and reassured them that the collected data will be secrete and confidential.

- Providing the students, the website link to fill out the study tools online (pre).

- Creating a WhatsApp group for students whom were participating in the study to clarify and answer any questions related to the study tools.

- Preparing the sleep instructional guidelines booklet according to the students' needs assessment.

- Sending the sleep instructional guidelines booklet for the students through their email.

- Waiting for one month later after sending the sleep instructional guidelines booklet.

- Asking the students to fill out the study tools again through the website link online (post).

\subsection{Administrative design}

An official permission was obtained from vice dean of academic affairs for data collection in the previously mentioned study setting through submission of an official letter produced from Faculty of Nursing at Umm Al-Qura University, then an oral agreement was obtained from the nursing students whom were participating in the study.

\subsection{Statistical design}

The data collected, organized, revised, coded, tabulated and analyzed through using SPSS version 25. Proper statistical tests used for finding out the effect of fostering the sleep instructional guidelines on the students. The following statistical techniques were used; numbers and percentage, Chisquare $\left(\chi^{2}\right), t$ test and proportion probability of error $(p$ value), whereas significance of results as follow: When $p>$ .05 it is statistically insignificant difference and when $p<.05$ it is statistically significant difference.

\subsection{Ethical considerations}

- An official permission obtained through the appropriate channels before data collection.

- Clear and simple clarifications of the study aim, and the expected outcomes explained to the nursing students.

- Applying code number for each student to protect confidentiality.

- The student was not exposing to any physical or psychosocial harms.

\subsection{Limitations of the study}

The current study was planned to be carried out all over the first semester to compare its effect in comparison to students' academic performance and class attendance/semester not per last moth only, but due to delaying of approving latter to collect data this interfere with the time to collect data from students and providing them with instructional guidelines.

\section{Results}

Figure 1 showed that, slightly more than three quarters (78.82\%) of nursing students were with their ages ranged from $20-22$ years. Whereas, $16.47 \%$ of them were $<20$ years and the rest of them $(4.71 \%)$ were $>22$ years.

Figure 2 revealed that, more than two thirds $(69.41 \%)$ of nursing students' gender were females, and the rest of them $(30.59 \%)$ were males.

Figure 3 illustrated that, $45.88 \%$ of nursing students were in the second year, and $32.94 \%$ of them were in the third year and the rest of them $(21.18 \%)$ were in the fourth year. 


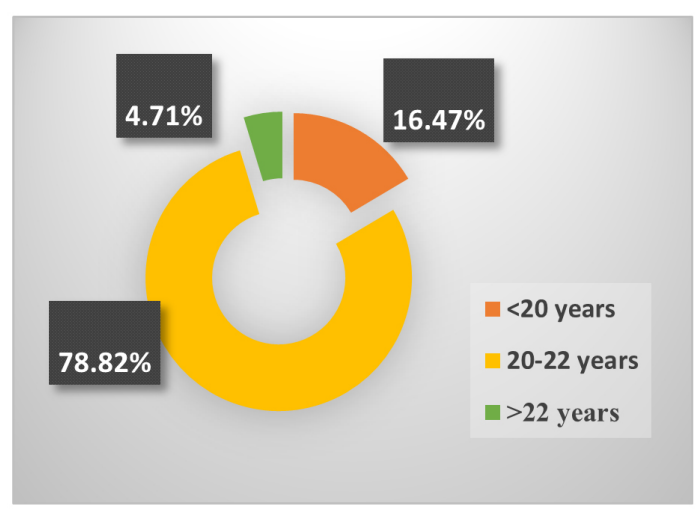

Figure 1. Distribution of students as regards their age

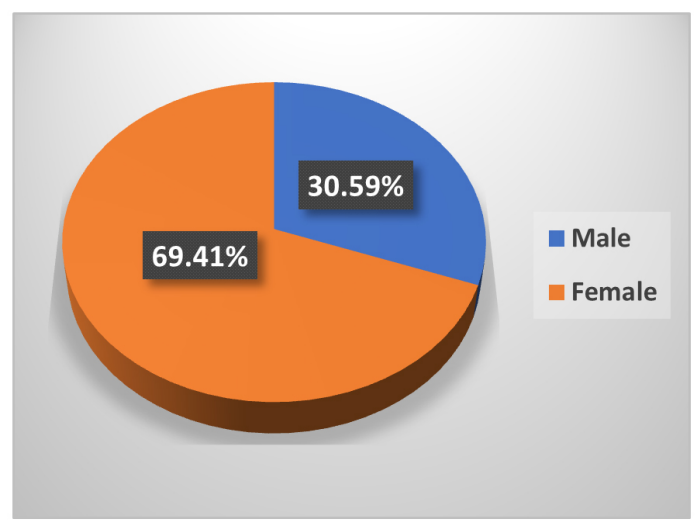

Figure 2. Distribution of students as regards their gender

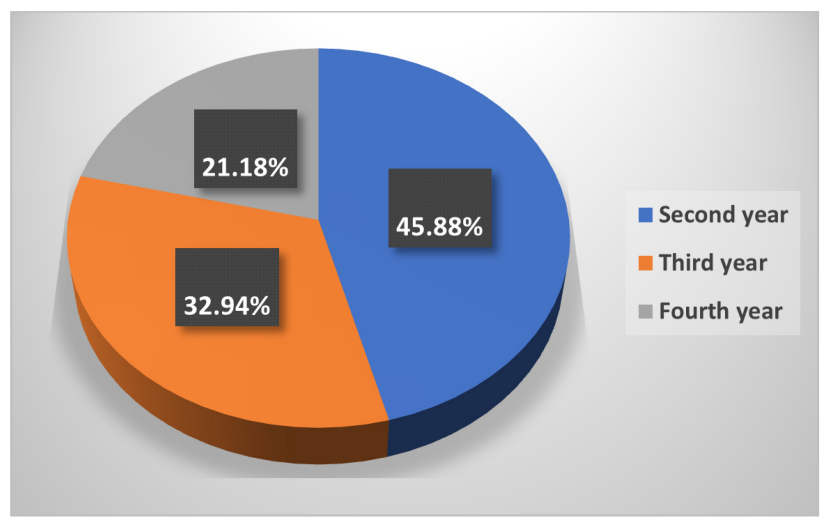

Figure 3. Percentage distribution of students according to their academic year

As regards students' social circumstances, Table 1 showed that most $(92.94 \%)$ of students were single, meanwhile $5.88 \%$ and $1.18 \%$ of them were married and divorced respectively. In relation to students' family type, this table represented that $82.35 \%$ of students were living in nuclear family and the rest $(17.65 \%)$ of them were living in extended family. In addition, $41.17 \%$ of students having family problems and the main causes of family problems were death of parents, divorce of parents, rigidity of parents and chronic diseases of parents or sibling as reported by $3.52 \%, 4.70 \%$, $8.23 \%$ and $17.64 \%$ of them respectively. Also, more than half $(56.47 \%)$ of students were not roommate or bed shared.

Table 1. Distribution of Students as Regards their Social Circumstances

\begin{tabular}{|c|c|c|}
\hline \multirow{2}{*}{ Social Circumstances } & \multicolumn{2}{|c|}{ Total No. $85=100 \%$} \\
\hline & No. & $\%$ \\
\hline \multicolumn{3}{|l|}{ Marital status } \\
\hline -Single & 79 & 92.94 \\
\hline -Married & 5 & 5.88 \\
\hline Divorced & 1 & 1.18 \\
\hline \multicolumn{3}{|l|}{ Having children } \\
\hline Yes & 1 & 1.18 \\
\hline No & 5 & 5.88 \\
\hline \multicolumn{3}{|l|}{ Type of family } \\
\hline Nuclear & 70 & 82.35 \\
\hline Extended & 15 & 17.65 \\
\hline \multicolumn{3}{|l|}{ Family problems } \\
\hline Yes & 35 & 41.17 \\
\hline No & 50 & 58.82 \\
\hline \multicolumn{3}{|l|}{ Causes of family problems** } \\
\hline -Death of parents & 3 & 3.52 \\
\hline -Divorce of parents & 4 & 4.70 \\
\hline -Rigidity of parents & 7 & 8.23 \\
\hline -Chronic diseases of parents/sibling & 15 & 17.64 \\
\hline -Others & 21 & 24.70 \\
\hline \multicolumn{3}{|l|}{ Extra-circular activities } \\
\hline Yes & 32 & 37.65 \\
\hline No & 53 & 62.35 \\
\hline \multicolumn{3}{|l|}{ Roommate or bed sharing } \\
\hline Yes & 37 & 43.53 \\
\hline No & 48 & 56.47 \\
\hline
\end{tabular}

**Numbers are not mutually exclusive.

On studying students' sleeping patterns as regards their subjective sleep quality according to PSQI, Table 2 demonstrated that $8.24 \%$ and $35.30 \%$ of students had very good and fairly good sleep pre compared to $17.64 \%$ and $51.76 \%$ of them post providing the sleep instructional guidelines booklet respectively, which reflected statistical significant difference ( $t=3.40$ at $p$-value .00). Regarding students' sleep latency, also this table showed that $12.94 \%$ of students got sleep less than 15 minutes pre compared with $31.76 \%$ post providing the sleep instructional guidelines booklet with statistical significant difference ( $t=3.02$ at $p$-value .00). Additionally, this table clarified that $25.88 \%$ of students' sleep efficiency was more than $85 \%$ pre compared with $85.88 \%$ post providing 
the sleep instructional guidelines booklet, that indicated statistical significant difference $(t=1.95,10.03$ at $p$-values .05 , $.00)$.

Table 2. Distribution of Students regarding their Sleeping Patterns According to Pittsburgh Sleep Quality Index Pre and Post Instructional Guidelines

\begin{tabular}{|c|c|c|c|c|}
\hline Items & Pre\% & Post \% & $t$ test & $\begin{array}{l}p \\
\text { value }\end{array}$ \\
\hline \multicolumn{5}{|c|}{ I. Subjective sleep quality } \\
\hline Very Good & 8.24 & 17.64 & \multirow{4}{*}{3.40} & \multirow{4}{*}{$.00 *$} \\
\hline Fairly Good & 35.30 & 51.76 & & \\
\hline Fairly Bad & 44.70 & 24.70 & & \\
\hline Very Bad & 11.76 & 5.90 & & \\
\hline \multicolumn{5}{|c|}{ II. Sleep latency/minutes } \\
\hline$<15$ & 12.94 & 31.76 & \multirow{4}{*}{3.02} & \multirow{4}{*}{$.00 *$} \\
\hline $16-30$ & 37.64 & 37.64 & & \\
\hline $31-60$ & 36.48 & 23.55 & & \\
\hline$>60$ & 12.94 & 7.05 & & \\
\hline \multicolumn{5}{|c|}{ III. Sleep duration/hours } \\
\hline$>7$ & 20 & 11.76 & \multirow{4}{*}{0.68} & \multirow{4}{*}{.49} \\
\hline $6-7$ & 21.17 & 22.36 & & \\
\hline $5-<6$ & 28.25 & 40 & & \\
\hline$<5$ & 30.58 & 25.88 & & \\
\hline \multicolumn{5}{|c|}{ A. Getting up time in the morning } \\
\hline Before 6 am & 35.29 & 37.65 & \multirow{3}{*}{1.04} & \multirow{3}{*}{.29} \\
\hline At 6 am & 27.05 & 35.29 & & \\
\hline After 6 am & 37.66 & 27.06 & & \\
\hline \multicolumn{5}{|c|}{ B. Bedtime at night } \\
\hline Before $8 \mathrm{pm}$ & 3.53 & 5.88 & \multirow{5}{*}{1.95} & \multirow{5}{*}{$.05^{*}$} \\
\hline 8 - before $10 \mathrm{pm}$ & 34.12 & 48.24 & & \\
\hline $10-2 \mathrm{am}$ & 52.94 & 38.82 & & \\
\hline After 2 am & 9.41 & 7.06 & & \\
\hline \multicolumn{3}{|c|}{ C. Sleep efficiency \% } & & \\
\hline$>85$ & 25.88 & 85.88 & \multirow{4}{*}{10.03} & \multirow{4}{*}{$.00^{*}$} \\
\hline $75-84$ & 29.41 & 11.76 & & \\
\hline $65-74$ & 21.18 & 2.36 & & \\
\hline$<65$ & 23.53 & 0 & & \\
\hline
\end{tabular}

Regarding students' sleep disturbances according to PSQI, Table 3 clarified that there was statistical significant difference $\left(\chi^{2}=187.09\right.$ at $p$-value .00$)$ pre and post providing the sleep instructional guidelines. Whereas, $24.70 \%, 24.70 \%$, $25.88 \%$ and $25.88 \%$ of students were complaining from feeling too cold, feeling too hot, had bad dreams, and had pain less than once a week pre the instructional guidelines compared with $35.29 \%, 24.72 \%, 17.66 \%$ and $24.70 \%$ post pro- viding the sleep instructional guidelines respectively.

Additionally, Table 3 explained that slightly more than half of the students hadn't bad dreams pre compared with more than two thirds (83.54\%) of them post the instructional guidelines. Also, the majority (85.88\%) of students weren't use sleep medication during the past month pre providing the instructional guidelines compared with most $(91.78 \%)$ of them post the sleep instructional guidelines, which reflected statistical significant difference $\left(\chi^{2}=2.27\right.$ at $p$-value .02$)$. In addition, approximately half of students $(47.06 \%)$ were complaining from insomnia three and more times/week pre compared with $91.77 \%$ of them were not complaining from insomnia during the past month post providing the sleep instructional guidelines booklet.

Regarding students' sleepiness situations according to ESS, Table 4 showed that there was statistical significant difference $\left(\chi^{2}=49.92\right.$ at $p$-value .00$)$ pre and post providing the sleep instructional guidelines booklet.

As regards the total score level of students' sleepiness state according to ESS, Table 5 clarified that $20 \%$ of students were getting enough sleep pre compared with $24.71 \%$ post providing the sleep instructional guidelines booklet, also $70.59 \%$ and $52.94 \%$ were seeking advice of sleep specialist without delay pre and post providing the sleep instructional guidelines booklet respectively that indicated statistical significant difference $\left(\chi^{2}=7.04\right.$ at $p$-value .02$)$.

As regards the total score level of students sleep quality, Table 6 demonstrated that more than one fourth $(27.06 \%)$ of students were having good sleep and $72.94 \%$ of them had poor sleep pre providing the instructional guidelines compared with $81.18 \%$ and $18.82 \%$ of them post providing the instructional guidelines booklet respectively which reflected statistical significant difference $\left(\chi^{2}=50.12\right.$ at $p$-value .00$)$.

As regards students' academic performance, Table 7 clarified that $36.47 \%$ and $27.06 \%$ of students had good and average academic performance respectively and the rest (36.47\%) of them had poor performance pre providing instructional guidelines compared to $68.24 \%, 25.88 \%$ and $5.88 \%$ of them respectively post providing instructional guidelines. Concerning the missed class attendance, this table also showed that $21.18 \%$ of students didn't missed classes and $35.30 \%$ of them missed 1-6 class/day and $27.05 \%$ were missed $\geq$ 15class/day pre providing the sleep instructional guidelines booklet compared to $43.53 \%, 31.77 \%$ and $12.94 \%$ of them respectively post providing the sleep instructional guidelines booklet. 
Table 3. Distribution of Students regarding their Sleeping Disruption According to Pittsburgh Sleep Quality Index Pre and Post Instructional Guidelines

\begin{tabular}{|c|c|c|c|c|c|c|c|c|c|c|}
\hline \multirow[b]{2}{*}{ Items } & \multicolumn{4}{|l|}{ Pre \% } & \multicolumn{4}{|l|}{ Post \% } & \multirow[b]{2}{*}{$\chi^{2}$} & \multirow[b]{2}{*}{$\begin{array}{l}p \\
\text { Value }\end{array}$} \\
\hline & $\begin{array}{l}\text { Not } \\
\text { during } \\
\text { the past } \\
\text { month }\end{array}$ & $\begin{array}{l}\text { Less } \\
\text { than } \\
\text { once a } \\
\text { week }\end{array}$ & $\begin{array}{l}\text { Once } \\
\text { or } \\
\text { twice a } \\
\text { week }\end{array}$ & $\begin{array}{l}\text { Three or } \\
\text { more } \\
\text { times a } \\
\text { week }\end{array}$ & $\begin{array}{l}\text { Not } \\
\text { during } \\
\text { the past } \\
\text { month }\end{array}$ & $\begin{array}{l}\text { Less } \\
\text { than } \\
\text { once } \\
\text { a week }\end{array}$ & $\begin{array}{l}\text { Once } \\
\text { or } \\
\text { twice a } \\
\text { week }\end{array}$ & $\begin{array}{l}\text { Three } \\
\text { or more } \\
\text { times } \\
\text { a week }\end{array}$ & & \\
\hline \multicolumn{11}{|l|}{ I .Sleep Disturbances } \\
\hline Can't get to sleep within $30 \mathrm{~min}$. & 30.60 & 15.29 & 34.11 & 20 & 44.70 & 25.88 & 18.82 & 10.58 & \multirow{7}{*}{187.09} & \multirow{7}{*}{$.00^{*}$} \\
\hline Cannot breathe comfortably. & 85.88 & 7.06 & 5.88 & 1.18 & 81.18 & 10.59 & 7.06 & 1.18 & & \\
\hline Cough or snore loudly. & 78.82 & 15.29 & 3.54 & 2.35 & 83.54 & 8.23 & 7.06 & 1.18 & & \\
\hline Feel too cold. & 58.84 & 24.70 & 10.58 & 5.88 & 37.66 & 35.29 & 17.64 & 9.41 & & \\
\hline Feel too hot. & 57.64 & 24.70 & 12.96 & 4.70 & 60 & 24.72 & 14.11 & 1.18 & & \\
\hline Had bad dreams/night mares. & 52.96 & 25.88 & 14.11 & 7.06 & 69.41 & 17.66 & 8.23 & 4.70 & & \\
\hline Have pain. & 60 & 25.88 & 9.42 & 4.70 & 62.35 & 24.70 & 10.60 & 2.35 & & \\
\hline II. Use of sleeping medications & 85.88 & 9.41 & 1.18 & 3.53 & 91.77 & 2.35 & 4.70 & 1.18 & 0.77 & .44 \\
\hline III. Day Time Dysfunction & 12.94 & 63.53 & 22.35 & 1.18 & 30.59 & 50.59 & 17.64 & 1.18 & 2.27 & $.02 *$ \\
\hline \multicolumn{5}{|l|}{ IV. Sleep Problems } & & & & & 3.02 & \multirow{3}{*}{$.00 *$} \\
\hline Insomnia. & 8.23 & 21.18 & 23.53 & 47.06 & 91.77 & 2.35 & 4.70 & 1.18 & & \\
\hline Hypersomnia. & 52.96 & 25.88 & 14.11 & 7.06 & 81.18 & 10.59 & 7.06 & 1.18 & & \\
\hline
\end{tabular}

Table 4. Distribution of Students' Sleepiness Situations according to Epworth Sleepiness Scale Pre and Post Instructional Guidelines

\begin{tabular}{|c|c|c|c|c|c|c|c|c|}
\hline \multirow{3}{*}{ Students' Sleepiness Situations } & \multicolumn{8}{|c|}{ Student's Scores } \\
\hline & \multicolumn{4}{|l|}{ Pre \% } & \multicolumn{4}{|c|}{ Post \% } \\
\hline & $\mathbf{0}$ & 1 & 2 & 3 & $\mathbf{0}$ & 1 & 2 & 3 \\
\hline Sitting and reading. & 27.06 & 32.94 & 22.35 & 17.65 & 30.59 & 35.29 & 25.88 & 8.24 \\
\hline Watching TV. & 29.41 & 36.47 & 28.24 & 5.88 & 36.47 & 21.18 & 30.59 & 11.76 \\
\hline Sitting in a public place inactive. & 34.12 & 22.35 & 28.24 & 15.29 & 40 & 21.18 & 23.53 & 15.29 \\
\hline As a passenger in car without a break for an hour. & 30.59 & 17.65 & 20 & 31.76 & 21.18 & 27.06 & 22.35 & 29.41 \\
\hline $\begin{array}{l}\text { Lying down when circumstances permit to rest in the } \\
\text { afternoon. }\end{array}$ & 2.35 & 10.59 & 21.18 & 65.88 & 7.06 & 14.12 & 36.47 & 42.35 \\
\hline Sitting and talking to someone. & 81.18 & 18.82 & 0 & 0 & 84.71 & 10.59 & 4.71 & 0 \\
\hline Sitting after a lunch quietly without coffee. & 9.41 & 23.53 & 35.29 & 31.76 & 21.18 & 30.59 & 24.71 & 23.53 \\
\hline In a car, while stooped for a few minutes in the traffic. & 56.47 & 23.53 & 16.47 & 3.53 & 62.35 & 22.35 & 8.24 & 8.30 \\
\hline$\chi^{2}$ & 49.92 & & & & & & & \\
\hline$p$ value & $.00 *$ & & & & & & & \\
\hline
\end{tabular}

Table 5. Total Score Level of Students' Sleepiness State according to Epworth Sleepiness Scale Pre and Post Instructional Guidelines

\begin{tabular}{|c|c|c|c|c|c|c|}
\hline \multirow{2}{*}{ Students' Sleepiness State } & \multicolumn{2}{|l|}{ Pre } & \multicolumn{2}{|c|}{ Post } & \multirow{2}{*}{$\chi^{2}$} & \multirow{2}{*}{$p$ value } \\
\hline & No. & $\%$ & No. & $\%$ & & \\
\hline Enough sleep (1- 6) & 17 & 20 & 21 & 24.71 & 19.00 & .21 \\
\hline Average sleep (7- 8) & 8 & 9.41 & 19 & 22.35 & 13.50 & 2.24 \\
\hline Need to seek advice of sleep specialist without delay $(\geq 9)$ & 60 & 70.59 & 45 & 52.94 & 52.50 & 1.07 \\
\hline$\chi^{2}$ & 7.04 & & & & & \\
\hline$p$ Value & $.02 *$ & & & & & \\
\hline
\end{tabular}


Table 6. Total Score Level of Students' Sleep Quality According to Pittsburgh Sleep Quality Index Pre and Post Instructional Guidelines

\begin{tabular}{llllll}
\hline \multirow{2}{*}{$\begin{array}{l}\text { Students' Sleep } \\
\text { Quality }\end{array}$} & Pre & & & Post \\
\cline { 2 - 3 } \cline { 5 - 6 } \cline { 5 - 5 } Good Sleep & No. & \% & & No. & \% \\
Poor Sleep & 62 & 72.94 & & 16 & 18.82 \\
$\chi^{2}$ & 50.12 & & & \\
$p$ value & $.00^{*}$ & & & \\
\hline * $p$-value $\leq .05$ statistical significant differences & &
\end{tabular}

${ }^{*} p$-value $\leq .05$ statistical significant differences
Regarding the students' psychosocial behavior, Table 8 confirmed that there was statistical significant differences $\left(\chi^{2}=\right.$ $7.99,5.03$, and 7.44 and at $p$-values $.01, .02, .00$ and .00$)$ pre and post providing the sleep instructional guidelines booklet in relation to student's consuming coffee in the evening, bedroom quiet and dark and use of smart phone games or social media respectively. Meanwhile, $62.35 \%$ of students were spending four hours or more on social media and internet pre compared with approximately half of them (57.66\%) post providing the sleep instructional guidelines booklet with statistical significant difference $\left(\chi^{2}=-0.81\right.$ at $p$-value 0.41$)$.

Table 7. Distribution of Students regarding their Academic Performance and Missed Class Attendance Pre and Post Instructional Guidelines

\begin{tabular}{|c|c|c|c|c|c|c|}
\hline \multirow{2}{*}{ Items } & \multicolumn{2}{|l|}{ Pre } & \multicolumn{2}{|l|}{ Post } & \multirow{2}{*}{$\chi^{2}$} & \multirow{2}{*}{$p$ Value } \\
\hline & No. & $\%$ & No. & $\%$ & & \\
\hline \multicolumn{7}{|c|}{ I. Academic Performance } \\
\hline Good & 31 & 36.47 & 58 & 68.24 & \multirow{3}{*}{26.99} & \multirow{3}{*}{$.00^{*}$} \\
\hline Average & 23 & 27.06 & 22 & 25.88 & & \\
\hline Poor & 31 & 36.47 & 5 & 5.88 & & \\
\hline \multicolumn{7}{|c|}{ II. Missed Class attendance/day } \\
\hline None & 18 & 21.18 & 37 & 43.53 & \multirow{4}{*}{11.62} & \multirow{4}{*}{$.00^{*}$} \\
\hline $1-6$ & 30 & 35.30 & 27 & 31.77 & & \\
\hline $7-14$ & 14 & 16.47 & 10 & 11.76 & & \\
\hline$\geq 15$ & 23 & 27.05 & 11 & 12.94 & & \\
\hline
\end{tabular}

Regarding the relationship between the total score level of students' sleep quality and their gender, Table 9 showed that there was statistical significant relation $\left(\chi^{2}=51.32\right.$ at $p$-value .00) between male and female sleep quality pre and post providing the sleep instructional guidelines booklet.

Regarding the relationship between total score level of students' sleep quality and their academic performance, Table 10 illustrated that there was statistical significant relation $\left(\chi^{2}\right.$ $=100.47$ at $p$-value .00 ) between students' sleep quality and their academic performance pre and post providing instructional guidelines. Whereas, $24.70 \%$ of students whom their sleep quality was good, they were had good academic performance pre the instructional guidelines compared with slightly more than two thirds $(67.07 \%)$ of them post providing the instructional guidelines.

\section{Discussion}

Sleep is a repetitive, an active and reversible behavior having different functions, such as learning and restorative processes, in addition to repair and growth. All these occur throughout the brain and the body. On the other hand, Sleep is

Published by Sciedu Press necessary for college students' intellectual, emotional and physical health, also for their cognitive performance that significantly affected by sleep quality. Thus, sleep is important for the cognitive functions for academic and social success in higher education El Desouky et al. (2015) and Harvey et al. (2017). ${ }^{[3,22]}$ Therefore, this study aimed to investigate the effect of fostering the sleep instructional guidelines for nursing students regarding their sleep quality, academic performance and psychosocial behavior.

According to the characteristics of nursing students, the results of this study revealed that slightly more than three quarters of students their age was 20-22 years and less than one quarter their age was $<20$ years and very few of them was $>22$ years. In addition, more than two thirds of nursing students were females, and more than one quarter of them were males, approximately half of students were in the second year, and one third of them were in the third year and the rest of them were in the fourth year. The findings of the current study were like the results of Khin Thandar et al. $(2016)^{[23]}$ when studied the relationship between quality of sleep and academic performance of female nursing students 
(2016) and Liu et al. $(2017)^{[3,23,25]}$ who mentioned that up to half of the students was rated as fairly good, only $1 \%$ represented very bad sleep quality during the past month , the rest of them their subjective sleep quality was very good and fairly bad which recorded as $28 \%$ and $16 \%$ respectively.

Table 10. Relationship between Total Score Level of Students'Sleep Quality and their Academic Performance Pre and Post Instructional Guidelines

\begin{tabular}{|c|c|c|c|c|c|c|c|c|}
\hline \multirow{4}{*}{$\begin{array}{l}\text { Academic } \\
\text { Performance }\end{array}$} & \multicolumn{4}{|c|}{ Total No. $85=100 \%$} & \multicolumn{4}{|c|}{ Total No. $85=100 \%$} \\
\hline & \multicolumn{4}{|l|}{ Pre } & \multicolumn{4}{|c|}{ Post } \\
\hline & \multicolumn{2}{|c|}{ Good sleep } & \multicolumn{2}{|c|}{ Poor Sleep } & \multicolumn{2}{|c|}{ Good sleep } & \multicolumn{2}{|c|}{ Poor Sleep } \\
\hline & No. & $\%$ & No. & $\%$ & No. & $\%$ & No. & $\%$ \\
\hline Good & 21 & 24.70 & 10 & 11.76 & 57 & 67.07 & 1 & 1.17 \\
\hline Average & 2 & 2.35 & 21 & 24.70 & 11 & 12.94 & 11 & 12.94 \\
\hline Poor & 0 & 0.00 & 31 & 36.47 & 1 & 1.17 & 4 & 4.71 \\
\hline$\chi^{2}$ & 100.47 & & & & & & & \\
\hline$p$ Value & $.00 *$ & & & & & & & \\
\hline
\end{tabular}

As regard students' sleep duration and getting up time in the morning, the current study pointed out that there was no statistically significant difference pre $\&$ post providing the sleep instructional guidelines booklet. Whereas, half of students were sleeping less than 6 hours before providing the instructional guidelines compared with two thirds of them post providing the instructional guidelines. These results are supported by Galambos et al. (2017) and Kabrita and Sleep Foundation Orgnizition (2017) ${ }^{[26,27]}$ who found that more than half of students sleep from 4-6 hours. Also, Hajjar-Muça (2016) and Sidddiqui et al. (2016) ${ }^{[28,29]}$ showed that students whom were sleeping 7 hours at night do better on cognitive works than others. As well as, Perfect et al. (2014) ${ }^{[15]}$ studied the contribution of sleep problems to academic and psychosocial functioning and mentioned that college students vary in terms of how much sleep is the right duration, but most of them need at least 6-8 hours a night.

According to Neinstien et al. (2017) ${ }^{[5]}$ who recommended that getting eight hours or more of sleep per night. If a student reduces the amount of sleep by only one hour in a night, it still has a significant impact on next day functioning, ability to focus, and performance at a college can all adversely affected. Mortality rate in people who sleep more than 8.5 hours or less than 3.5 hours at nights is $15 \%$ more than people who sleep 7 hours in average every night. Additionally, variety of sleep measures, including consistency \& length of sleep, satisfaction with sleep and frequency of sleep problems have deteriorated in the college students over several decades. ${ }^{[10,25]}$

On investigating the students' sleeping according to PSQI concerning students' sleep disturbances, this study confirmed

Published by Sciedu Press that there was statistically significant difference in relation to sleep disturbances pre and post providing the sleep instructional guidelines. Whereas, approximately one fourth of students were complaining from feeling too cold, feeling too hot, had bad dreams /nightmares and had pain less than once a week pre providing the sleep instructional guidelines compared with very few of them post. In addition, approximately half of students were complaining from insomnia $\geq 3$ times/week compared with many of them were not complaining from insomnia during the past month pre and post providing the sleep instructional guidelines respectively. These results may attribute to environmental factors and the sleeping habits of college students such as late-night study, excessive use of internet and caffeine intake, also intense academic demands among college students particularly nursing students causing they had the least amount of sleep. Perfect et al. (2014) ${ }^{[15]}$ stated that up to one fourth of nursing students were suffering from sleeping disorders. Unfortunately, college students are more likely to report sleeping disturbances than the public and several studies revealed a high prevalence of sleeping disturbances within this group of population.

According to Harvey et al. (2017) ${ }^{[22]}$ who pointed out that certain medical problems such as narcolepsy, chronic sleep deprivation, depression, hypersomnia of unknown cause and obstructive sleep apnea (OSA) disrupt sleep. It also understood that many students were not aware of their poor sleep quality or their sleep deprivation. Therefore, they may not seek advice regarding this problem. Moreover, Liu et al. (2017) ${ }^{[25]}$ mentioned that students complaining of sleeping disturbances reported increased depression, inattention, anxiety, impaired academic performance, conduct problems, 
insomnia and nightmares, suicidal thoughts and behaviors.

Additionally, sleep problems cause adverse educational and psychosocial functioning, as indicated by special education referrals or performance on psycho educational evaluations. Whereas, assessment of sleep is not currently part of routine faculty wide screenings and comprehensive assessments Therefore, the potential contributions of sleep disorders and the relations of insufficient sleep to poor academic performance may not identified. Thus, college social specialists and psychologists need to be aware for different aspects of sleep wake behavior problems that may contribute to poorer outcomes for adolescents. ${ }^{[6]}$

Furthermore, the findings of this study confirmed that, few of students can't fall asleep within 30 minutes after going to bed $\geq 3$ times/week pre compared with very few of them post providing them the sleep instructional guidelines. More than three quarters of them told that they had not cough loudly or snoring any time through last month, pre compared with most of students post. These findings agreed with El Desouky et al. $(2015)^{[3]}$ who showed that $44.5 \%$ of the students can't fall asleep within 30 minutes after going to bed $\geq 3$ times/week, $39 \%$ of students must get up to use the bathroom less than one time per a week. Also, up to two thirds of them told that they had not cough loudly or snoring any time through last month for and more than one quarter of the students have horrible dreams from 1-2 times/week. Furthermore, less than one quarter of the students had pain three times or more per week at last month. Only $19 \%$ of students at last month had very good sleep quality and approximately one quarter of them had difficulty to get in sleeping from 1 or 2 times per week. Furthermore, less than half of the students faced simple problems and affected on practicing activities with highly statistically significant difference. Meanwhile, KhinThandar et al. (2016) ${ }^{[23]}$ clarified that many of students have daytime sleepiness.

Concerning the use of sleeping medications and daytime dysfunction of students according to PSQI pre and post providing the sleep instructional guidelines booklet. The current study findings indicated that, most of students weren't use sleeping medication during the past month pre providing the instructional guidelines compared with most of them post the instructional guidelines with statistical significant difference. This result was corresponding with Neinstien et al. (2017) ${ }^{[5]}$ who stated that a minority of the respondents were using sleep medication in the past one month.

In contrast, Carskadon and Roth (2016) ${ }^{[14]}$ emphasized that increased likelihood of students' stimulant use (including caffeine and nicotine) and similar substances. Meanwhile, Zeek et al. (2015) and Galambos et al. $(2017)^{[4,26]}$ found that participant reported poor their subjective sleep quality and sleep efficiency, meanwhile they consumed less sleep medication, had less sleep disturbances and daytime dysfunction. This could be due to cultural differences in sleeping habits.

Regarding the total score level of students' sleepiness state according to ESS, the current study findings indicated statistical significant difference pre and post providing the sleep instructional guidelines. Whereas, less than one quarter of students were getting enough sleep pre compared with one quarter of them post, and approximately three fourths of students compared with half of them were seeking advice of sleep specialist without delay (score $\geq 9$ ) pre and post providing the sleep instructional guidelines respectively. These results were consistent with Sleep Foundation Orgnizition (2017) ${ }^{[27]}$ who reported that approximately one-third of the respondents had a score of 11 or higher on the ESS indicating a daytime sleepiness greater than $0.5 \%$ to $12 \%$ which is the expected rate of daytime sleepiness in the normal population.

As regards the total score level of students' sleep quality, the findings of this study showed that up to one quarter of students having good sleep and two thirds of them had poor sleep pre providing the sleep instructional guidelines compared with the majority and less than one fourth of them post providing the sleep instructional guidelines respectively, which reflected statistical significant difference. These findings were like the findings of Al Ghamdi (2013) ${ }^{[10]}$ who reported that between $43 \%-88 \%$ of students of medical sciences suffer from poor sleep quality.

In this context, KhinThandar et al. ( 2016) ${ }^{[23]}$ who stated that the majority of college students experienced poor sleep quality. Also, El Desouky et al. (2015) ${ }^{[3]}$ represented that approximately two thirds $(62.5 \%)$ of students their quality of sleep was poor, while few of them $(6 \%)$ their quality of sleep was good. Hence, nursing institutional education and responsible parties must plan for specific interventions in order to improve students' health problems concerning sleep quality.

On evaluating the effect of providing the sleep instructional guidelines on students' psychosocial behavior. The current study illustrated statistical significant differences pre and post providing the sleep instructional guidelines in relation to psychosocial problems in the form of students' social isolation, loneliness, anxiety, depression, fear and stress, in addition to student's consuming coffee in the evening, bedroom quiet and dark and use of social media. Meanwhile, approximately two thirds of students were spending four hours or more on smart phone/social media and use of internet pre providing the sleep instructional guidelines booklet compared with approximately half of them post providing 
the sleep instructional guidelines booklet, which indicated no statistical significant difference pre and post.

According to Raseki et al. (2016) ${ }^{[9]}$ who mentioned that sleep is one important factor that has been associated with psychosocial behavior and functioning among college students. In the same line Galambos et al. (2017) ${ }^{[26]}$ confirmed that prevalence rates of sleep problems and poor sleep quality among students ranging from $9.7 \%$ to $54.7 \%$. Whereas, poor quality of sleep and short its duration is associated with negative psychosocial functioning. These results may attribute to environmental factors and the sleeping habits of college students such as late-night study and excessive use of internet and smart phone that leads to excessive caffeine intake.

Furthermore, the psychosocial functioning is more strongly associated with sleep quality rather than sleep duration. Higher sleep quality on a given night was related to higher positive affect, lower negative affect, and lower stress the next day. ${ }^{[27]}$ Although many factors are responsible for altered sleep habits; such as use of smart phone, and social media and internet are important causes for going to sleep late. Another cause for going to sleep late is consuming of stimulants that affect the central nervous system such as caffeinated drinks and cocktails with alcohol. ${ }^{[28,30]}$

On studying the relationship between nursing students' total score sleep quality and their gender, this study showed statistically significant relation regarding males \& females sleep quality pre and post providing the sleep instructional guidelines booklet. Whereas, male nursing students has better sleep quality than female nursing students. These findings was agreeing with findings of Alos et al. (2015) and Lund et al. $(2017)^{[2,31]}$ who reported that high percentage of female students had short sleep duration and poor sleep quality. Controversy, Cates et al. (2015), Lai \& Say (2013) and Yun Ahn \& Ju Kim Y $(2015)^{[8,32,33]}$ found that sleep quality of female students wasn't worse than those of male students in terms of poor sleepers prevelance, and PSQI items and its total score.

On the other hand, Shibley et al. (2013) and Sajadi et al. $(2014)^{[34,35]}$ emphasized that most of male adolescent than female show use of computer games excessively at night and they are having problems that interfere with their social life and causing sleep disturbances. Students complaining of sleep disorders after playing computer gams, often have a long sleep duration throughout the day accompanied with poor sleep efficiency.

On examining students' sleep quality in relation to their academic performance and missed class attendance pre and post providing the sleep instructional guidelines, it was founded that this study demonstrated approximately two thirds of students had good and average academic performance pre compared with the majority of them post providing the sleep instructional guidelines booklet with statistical significant relation between student's sleep quality and their academic performance pre and post. The findings of this study were supported by Perfect et al. (2014), Seun-Fadipe and Mosaku (2017), Schmidt and Van der Linden $(2018)^{[15,36,37]}$ who emphasized on a significant relation between quality of sleep and students' academic performance.

In this context, Al Ghamdi (2013) ${ }^{[10]}$ highlighted on poor sleep quality was correlated with decreased academic performance. Whereas, students having lower Grade Point Average (GPA) category reported having poor sleep quality. College students showed similar finding and claimed that overall performance and concentration of poor sleepers may be affected due to difficulty in functioning all over the day. ${ }^{[20]}$

Furthermore, lack of sleep in college students has identified as one of the academic situational constraints that diminish students' performance. Students who stay up late tend to have lower academic performance, poor quality of sleep and maladjustment to college life. ${ }^{[18]}$ In the same context, KhinThandar et al. (2016) ${ }^{[23]}$ reported that there was a significant association between sleep quality and students' academic performance. Also, El Desouky et al. (2015), ${ }^{[3]}$ Seun-Fadipe and Mosaku (2017) ${ }^{[36]}$ identified the association between quality of sleep and its impact towards academic performance among nursing students at the faculty of nursing. Whereas students with good total sleep quality have good academic score with positive correlation with highly statistically significant difference.

Therefore, it is recommended that undergraduate nursing students should be educated about the importance of adequate sleep to their academic performance and high score achievement in their study. Sufficient daily sleep may also have an impact on their general physical and psychological wellbeing, this may attribute to the result of a physiological studies that confirmed, adequate sleep is necessary for adolescence memory consolidation which have important implications for their academic success. ${ }^{[30,38,39]}$

Finally, the current study pointed out on the importance of maintaining good sleep quality when promoting mental and physical health of nursing students as sleep problems can significantly impair students' academic performance that reflect negatively on their psychosocial behavior. Thus, in order to increase students' awareness towards their sleep quality, sleep education is highly recommended. So, students who consistently face sleeping disturbances should seek professional advices. As well as, students need to identify the 
positive correlation between good sleep quality with their academic achievement and psychosocial behavior.

\section{Conclusion}

Fostering the sleep instructional guidelines regarding had positive effects on nursing students' sleep patterns in the form of sleep quality, bedtime at night, sleeping latency, sleeping efficiency and disturbances. In addition to enhancing students' academic performance and modifying their psychosocial behavior regarding daytime dysfunction, coffee consuming in the evening, bedroom environment, social isolation, and use of social media. Moreover, there were statistically significant differences regarding students' sleep quality, sleepiness state and their academic performance. Meanwhile there were statistically insignificant differences regarding students' duration of sleep and time of awakening pre and post providing the instructional guidelines regarding sleep.

\subsection{Recommendations}

1) Maintaining students' sleep diary as a required document in the students' portfolio in the university.

2) Upgrading students' awareness about sleep, the harmful effects of sleep deprivation and the importance of applying and follow the sleep guidelines.

3) Requesting sleep education to be included in all higher education curriculums at all levels as a basic human needs and rights for students.

4) Asking the parents to be a good role model for their college students that make sleep a high priority for the family by practicing good sleep habits.

5) Future research should carry out for college students' sleep patterns on a broad category as a regional research project all over the Kingdom of Saudi Arabia involving multidisciplinary team as doctors, nurses, psychologists, sociologists and nutritionists.

\section{CONFLicts OF InTEREST Disclosure}

The authors declare that there is no conflict of interest.

\section{REFERENCES}

[1] Thomas C, McIntosh1 C, Lamar R, et al. Sleep deprivation in nursing students: The negative impact for quality and safety. Journal of Nursing Education and Practice. 2017; 7(5): 87-93. https: //doi.org/10.5430/jnep.v7n5p87

[2] Alos S, Caranto L, David J. Factors Affecting the Academic Performance of the Student Nurses of BSU. International Journal of Nursing Science. 2015; 5(2): 60-65.

[3] El Desouky EM, Lawend JA, Awed HM. Relationship between quality of sleep and academic performance Among Female Nursing Students. International Journal of Nursing Didactics. 2015; 5: 9 September.

[4] Zeek M, Savoie M, Song M, et al. Sleep Duration and Academic Performance Among Student Pharmacists. American Journal of Pharmaceutical Education. 2015; 79(5): Article 63. PMid:26396272 https://doi.org/10.5688/ajpe79563

[5] Neinstein LS, Gordon M, Katzaman K, et al. Adolescent Health Care: A Practical Guide. 6th ed. USA: Lippincott Williams \& Wilkins. 2017.

[6] Slats D, Claassen J, Verbeek M, et al. Reciprocal interactions between sleep, circadian rhythms and Alzheimer's disease: Focus on the role of hypocretin and melatonin. Ageing Research Reviews. 2016; 12: 188-200. PMid:22575905 https://doi.org/10.1016/ j.arr.2012.04.003

[7] Arne HE, Christopher JL, Arn HE. Early to bed, early to rise! Sleep habits and academic performance in college students. Sleep Breath 2017; 14: 71-75. PMid:19603214 https://doi.org/10.1007/ s11325-009-0282-2

[8] Cates ME, Clark A, Woolley TW, et al. Sleep quality among pharmacy students. American Journal of Pharmaceutical Education. 2015; 79(1): 09. PMid:25741025 https ://doi.org/10.5688/ajpe79 109
[9] Rasekhi, S. Ashouri, F, and Pirouza, A. Effects of Sleep Quality on the Academic Performance of Undergraduate Medical Students. Scope. 2016 August; 5(3):31641. https : //doi.org/10.17795/j healthscope-31641

[10] Al Ghamdi A. Sleep Deprivation and Academic Performance of Students in the Collage of Nursing at King Saud University. World Applied Sciences Journal. 2013; 27(2): 155-167.

[11] World Medical Association. Principles for medical research involving human subjects. October 2013. Available from: http: //www. wma.net/en/30publications/10polic

[12] Mandal M. What is Sleep? 2017. Available from: https : //www. ne ws-medical.net/health/What-is-sleep.aspx

[13] Smith BY. Function of Sleep. 2016. Available from: https : //www . news-medical .net/health/Function-of-Sleep.aspx

[14] Carskadon M, Roth T. 2016. Available from: https: //sleepfoundation.org/sites/default/files/slee p_and_teens_report1.pdf

[15] Perfect M, Levine-Donnerstein D, Archbold K, et al. The Contribution of Sleep Problems to Academic and Psychosocial Functioning. Psychology in the Schools. 2014; 51(3). https://doi.org/10.1 002/pits. 21746

[16] Johns M. A new method for measuring daytime sleepiness: the Epworth sleepiness scale. Sleep. 2010; 14(6): 540-545. PMid:1798888 https ://doi.org/10.1093/sleep/14.6.540

[17] Ali A, Majeed M, SabaK BA, et al. Effects of different sleeping patterns on academic performance in medical school students. Natural Science. 2013; 5(11): 1193-1198. https://doi.org/10.4236/ ns. 2013.511146

[18] Benavente S, Silva R, Higashi A, et al. Influence of stress factors and socio-demographic characteristics on the sleep quality of nursing students. Revista Da Escola De Enfermagem Da USP. 2014; 48(3): 514-520. PMid:25076281 https ://doi .org/10.1590/S0080-6 23420140000300018 
[19] Gaultney F. The prevalence of sleep disorders in college students: Impact on academic performance. The Journal of American College Health. 2017; 59: 91-97. PMid:20864434 https : //doi .org/10.1 $080 / 07448481.2010 .483708$

[20] Aung K, Nurumal M, Zainal S. Sleep Quality and Academic Performance of Nursing Students. Journal of Nursing and Health Science. 2016; 5(6): 145-149.

[21] Buysse J, Reynolds F, Monk H, et al. The Pittsburgh Sleep Quality Index (PQSI): A new instrument for psychiatric research and practice. Psychiatry Research. 2009: 28(2); 193-213. https : //doi .org/10 .1016/0165-1781 (89) 90047-4

[22] Harvey AG, Stinson K, Whitaker KL, et al. The subjective meaning of sleep quality: A comparison of individuals with and without insomnia. Sleep. 2017; 31(3): 383-393. PMid:18363315 https: //doi.org/10.1093/sleep/31.3.383

[23] KhinThandar A, MohdSaid N, Siti Nurhizwanybinti Z. Sleep Quality and Academic Performance of Nursing Students. IOSR Journal of Nursing and Health Science (IOSR-JNHS). 2016; 5(6): 145-149.

[24] Williamson K. Students finding less time for sleep as extracurricular activities add up. 2015. Available from: http://www.gainesvill etimes.com/archives/107248

[25] Liu X, Zhao Z, Jia C, et al. Sleep Patterns and Problems among Chinese Adolescents. Pediatrics. 2017; 127(6): 1165-1173.

[26] Galambos NL, Howard AL, Maggs JL. Rise and fall of sleep quantity and quality with student experiences across the first year of university. Journal of Research on Adolescence. 2017; 27: 342-349. https://doi.org/10.1111/j.1532-7795.2010.00679.x

[27] Sleep Foundation Orgnization. Healthy Sleep Tips. 2017. Available from: https://sleepfoundation.org/sleep-tools-t ips/healthy-sleep-tips

[28] Kabrita C, Hajjar-Muça T. Sex-specific sleep patterns among university students in lebanon: Impact on depression and academic performance. Nature and Science of Sleep. 2016; 8: 189-196. PMid:27382345 https://doi.org/10.2147/NSS.S104383

[29] Sidddiqui H, Al-Musa H, Al-Amri M, et al. Sleep Patterns and Predictors of Poor Sleep Quality among Medical Students in King Khalid University, Saudi Arabia. Malays J Med Sci. 2016; 23(6): 94-102.
PMid:28090183 https://doi.org/10.21315/mjms2016.23.6 .10

[30] Lowry M, Dean K, Manders K. Sleep the link between sleep quantity and academic performance for the college student.Neuropsychiatric Disease and Treatment. 2017.

[31] Lund H, Reider B, Whiting A, et al. Sleep patterns and predictors of disturbed sleep in a large population of college students. J Adolesc. Health. 2017; 46(2): 124-132. PMid:20113918 https : //doi.org/10.1016/j.jadohealth.2009.06.016

[32] Lai P, Say Y. Associated factors of sleep quality and behavior among students of two tertiary institutions in northern Malaysia. Med J Malaysia. 2013; 68(3): 196-203.

[33] Yun Ahn S, Ju Kim Y. The influence of Smart phone Use and Stress on Quality of Sleep among Nursing Students. Indian Journal of Science and Technology. 2015; 8(35). https://doi.org/10.17485 /ijst/2015/v8i35/85943

[34] Shibley H, Malcolm R, Veatch L. Adolescents with Insomnia and Substance Abuse: Consequences and Comorbidities. Journal of Psychiatric Practice. 2013; 14(3): 146-153. PMid:18520783 https : //doi.org/10.1097/01.pra.0000320113.30811.46

[35] Sajadi A, Farsi1 Z, Rajai N. Sleep Quality and the relationship between sleep quality with fatigue severity and academic performance of nursing students. Nursing Practice Today. 2014; 1(4): 213-220.

[36] Seun-Fadipe C, Mosaku K. Sleep quality and academic performance among Nigerian undergraduate students. Journal of Systems and Integrative Neuroscience. 2017; 3(5): 1-6. https ://doi .org/10.1 5761/JSIN. 1000179

[37] Schmidt R, Van der Linden M. The Relations Between Sleep, Personality, Behavioral Problems, and School Performance in Adolescents. Sleep Med Clin. 2018; 10(2): 117-23. PMid:26055859 https://doi.org/10.1016/j.jsmc.2015.02.007

[38] Waqas A, Khan S, Sharif W, et al. Association of academic stress with sleeping difficulties in medical students of a Pakistani medical school: a cross sectional survey. Peer J. 2015.

[39] Renau A, Fernandez D, Valls B, et al. The effect of sleep quality on academic performance is mediated by Internet use time: DADOS study. J. Pediatric (Rio J). 2018; 3(6). 